04.1;06.5

\title{
Нанесение аморфного металлического покрытия на полые стеклянные микросферы
}

\author{
() А.Ф. Паль, А.Н. Рябинкин, А.О. Серов \\ Научно-исследовательский институт ядерной физики им. Д.В. Скобельцына Московского государственного университета \\ им. М.В. Ломоносова, Москва, Россия \\ E-mail: aloleserov@yandex.ru
}

Поступило в Редакцию 29 декабря 2021 г.

В окончательной редакции 29 декабря 2021 г.

Принято к публикации 11 января 2022г.

С помощью магнетронного распыления на постоянном токе получены аморфные и кристаллические металлические покрытия $\mathrm{Pt}-\mathrm{Zr}$ на стеклянных полых тонкостенных сферах с диаметром в субмиллиметровом диапазоне при средней скорости нанесения $0.1 \mathrm{~nm} / \mathrm{s}$. Шероховатость полученных аморфных покрытий значительно ниже, чем у кристаллических покрытий того же состава, и находится в диапазоне $1-1.5 \mathrm{~nm}$.

Ключевые слова: металлические стекла, аморфные металлические пленки, магнетронное распыление, стеклянные микросферы, мишени для инерциального синтеза.

DOI: 10.21883/PJTF.2022.06.52212.19120

Получение металлических оболочек на сферах и частицах другой формы, имеющих размеры в микронном и миллиметровом диапазонах, востребовано в разработках покрытий, поглощающих электромагнитное излучение, в порошковой металлургии и катализе. Наиболее жесткие требования предъявляются к характеристикам покрытий на стеклянных сферах, которые в ряде случаев используются при изготовлении мишеней инерциального термоядерного синтеза (ИТС) [1]. Для их удовлетворения методы получения оболочек мишеней ИТС совершенствуются (например, введением ультразвука при гальваническом осаждении для уменьшения шероховатости [2], ионным ассистированием при магнетронном распылении для увеличения плотности [3]). Известен бесконтактный способ удержания в плазме легких микросфер при напылении оболочки, снижающий количество дефектов поверхности [4]. Получаемые оболочки имеют столбчатую кристаллическую структуру. Шероховатость и проницаемость аморфных металлических (AM) покрытий на больших плоских подложках могут быть значительно ниже, чем у пленок с зернистой кристаллической структурой [5-7]. Можно предположить, что и на сфере АМ-оболочка по этим параметрам будет превосходить кристаллические аналоги. В работе [7] установлено, что условия получения аморфного сплава магнетронным распылением в системе $\mathrm{Pd}-\mathrm{Zr}$ ограничены диапазоном низкой температуры подложки (менее $90^{\circ} \mathrm{C}$ ). Более высокая температура способствует получению кристаллических пленок в этой системе. Геометрические параметры полых стеклянных микросфер осложняют поддержание низкой температуры при напылении на них металла, поэтому возможность получения АМ-оболочки на таких сферах неочевидна. Цель настоящей работы - продемонстрировать возможность нанесения АМ-оболочки на полые сферы с диаметром на уровне размера внутренней оболочки двухоболочечной мишени ИТС.

Предварительно была проведена оценка стационарной температуры микросферы при воздействии теплового потока, который попадает на сферу при определенных режимах работы используемого магнетронного распылителя. Площадь соприкосновения сферы и кюветы считалась пренебрежимо малой. Рассматривались потери тепла за счет лучистого теплообмена между малой сферой и большой охлаждаемой камерой. Приведенная степень черноты для системы двух тел считалась равной 0.05 (полированная платина). Необходимая для оценки плотность теплового потока была измерена в предварительном эксперименте при помощи термозонда. Использованы методика измерений и конструкция зонда, близкие к применявшимся в работе [8]. Мишень и стенки камеры охлаждались водой, давление аргона составляло $0.4 \mathrm{~Pa}$, расстояние между зондом и мишенью было $8 \mathrm{~cm}$. Для значений разрядной мощности 50 и $140 \mathrm{~W}$ измеренная плотность потока составила 0.2 и $0.7 \mathrm{~kW} / \mathrm{m}^{2}$ соответственно. Согласно результатам оценки, этим значениям отвечает стационарная температура микросферы 190 и $320^{\circ} \mathrm{C}$ соответственно. Отметим, что использованная методика может давать несколько заниженное значение теплового потока и температуры сферы, поскольку в ней не учитывается обнаруженное в [9] различие скоростей охлаждения при включенном и выключенном магнетроне, наиболее актуальное при повышенной разрядной мощности. На основе результатов оценки для получения АМ-пленок на микросферах была выбрана бинарная система $\mathrm{Pt}-\mathrm{Zr}$, где по сравнению с системой $\mathrm{Pd}-\mathrm{Zr}$ ниже подвижность адатомов и выше температура расстеклования [10]. Сначала были получены и исследованы пленки $\mathrm{Pt}-\mathrm{Zr}$ на гладких пластинах размером $0.4 \times 20 \times 20 \mathrm{~mm}$ при различной температуре 


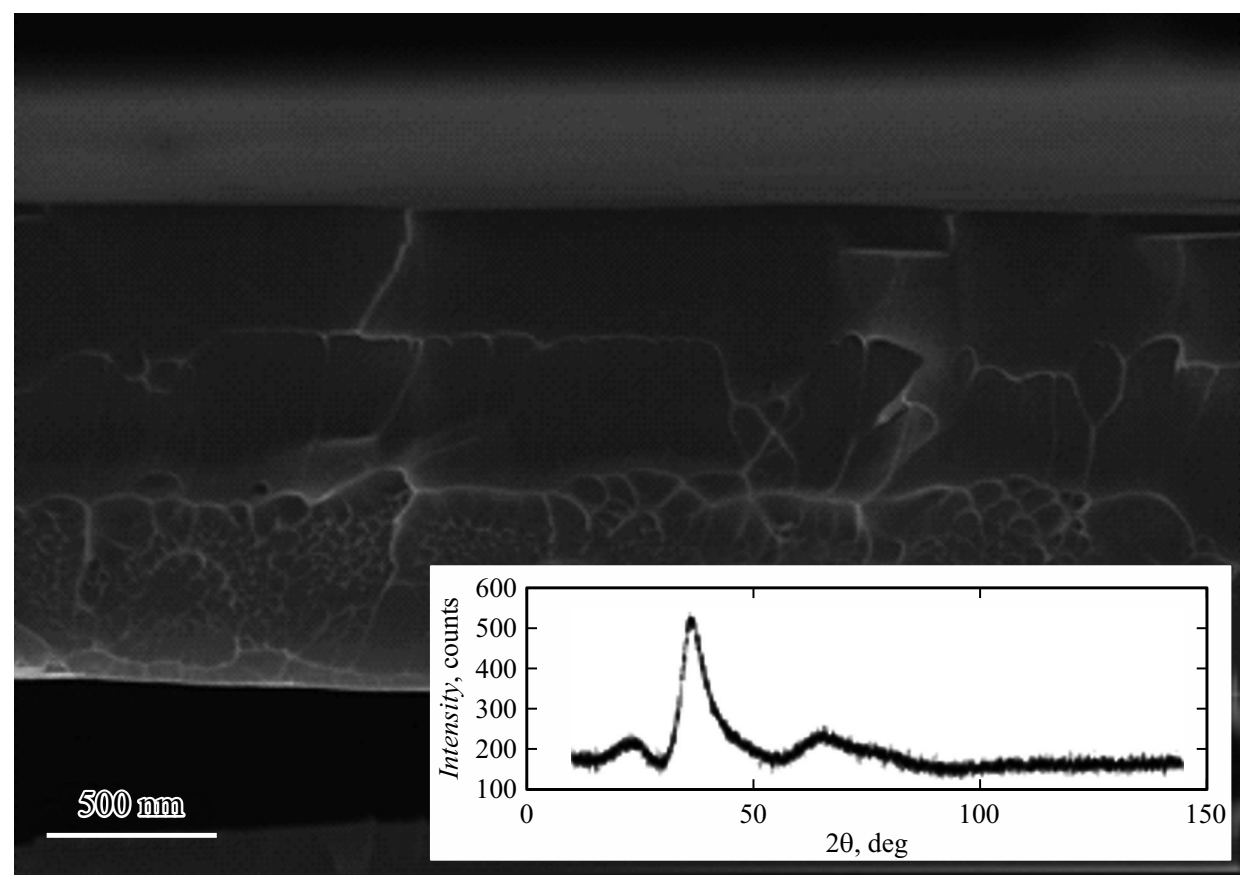

Рис. 1. Поверхность и поперечный излом аморфной пленки $\mathrm{Pt}: \mathrm{Zr}=1: 4$, нанесенной на плоскую подложку, и ее дифрактограмма (на вставке).

в диапазоне $60-380^{\circ} \mathrm{C}$. Результаты позволили уточнить детали необходимой оснастки установки и нанести АМпленки $\mathrm{Pt}-\mathrm{Zr}$ на полые стеклянные сферы диаметром $400-1000 \mu \mathrm{m}$ с толщиной стенки в диапазоне $1-3 \mu \mathrm{m}$.

Покрытия наносились при помощи планарного магнетронного распылителя с разбалансированной магнитной системой, оснащенного мозаичной мишенью [7]. Мишень представляла собой пластину диаметром $100 \mathrm{~mm}$ из циркония с платиновыми вставками в распыляемой области. При нанесении на плоские подложки мощность разряда распылителя составляла $480 \mathrm{~W}$, а при нанесении на микросферы мощность варьировалась от опыта к опыту в диапазоне 50-480 W. В обоих случаях давление аргона $0.4 \mathrm{~Pa}$ и расстояние мишень-подложка $8 \mathrm{~cm}$ соответствовали значениям, используемым в предварительных калориметрических измерениях. Плоские стеклянные и кремниевые подложки размещались на неподвижном держателе. Для варьирования температуры тепловой контакт подложек с держателем изменялся с помощью проставок. Сферические микроподложки приводились в движение в процессе напыления для равномерного нанесения покрытия на их поверхность. Для этого они размещались в подвижной массивной кювете с плоским дном. Этой кювете сообщалось колебательное движение извне вакуумной камеры. В результате этого движения наклон дна относительно горизонтальной плоскости периодически изменялся, это вызывало качение сфер по дну кюветы. Медленные перемещения периодически сопровождались ударным встряхиванием кюветы. Кювета с микросферами и неподвижный подложкодержатель были электрически изолированы от электродов разряда. Одновременно с пленками на микросферах росли пленки на плоской поверхности кюветы. Структура этих пленок также исследовалась. Покрытия были исследованы на автоэмиссионном сканирующем электронном микроскопе SUPRA 40 с приставкой INCA для рентгеноспектрального анализа. Рентгеновские дифрактограммы больших образцов записывались с помощью спектрометра на основе дифрактометра с источником $\mathrm{Cu} K_{\alpha}$-излучения. Шероховатость покрытий измерялась на атомном силовом микроскопе AIST-NT SPM (модель SmartSPM-1000) и на оптическом профилометре Profilm3D.

На плоских пластинах были получены пленки состава $\mathrm{Pt}: \mathrm{Zr}=1: 4$ при скорости роста $2.5 \mathrm{~nm} / \mathrm{s}$. Кристаллические фазы обнаружены только в пленках, полученных при температуре $350-380^{\circ} \mathrm{C}$. На рис. 1 показано изображение поверхности и поперечного излома, характерное для пленок, выросших при температуре подложки в диапазоне $60-320^{\circ} \mathrm{C}$. Разрушение пленок в верхней части имеет сдвиговый характер, свойственный металлическим стеклам. „Веноподобный“ вид нижней части излома также характерен для металлических стекол. Остальная часть поверхности излома, как и внешняя поверхность пленки, в масштабе от нескольких до сотен нанометров гладкая, без признаков зернистости. На вставке к рис. 1 приведена дифрактограмма показанной пленки. В ней наблюдаются гало, характерные для металлических стекол (с максимумами при 36 и 65). Гало при малых углах соответствует стеклу подложки. Пленки, выросшие на плоской поверхности подвижной кюветы, демонстрируют аналогичную структуру. 

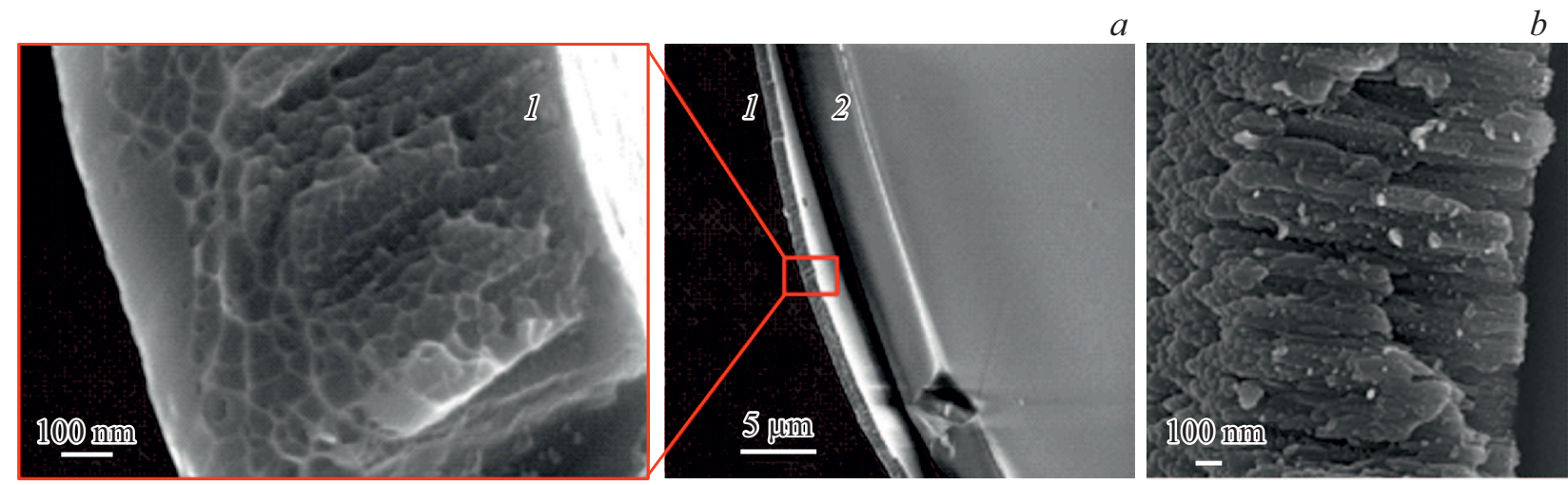

Рис. 2. Изображения излома аморфной металлической пленки $(a)$ и кристаллической пленки того же состава $(b)$ на сферах диаметром $0.5 \mathrm{~mm} .1$ - излом пленки, 2 - излом сферической подложки.
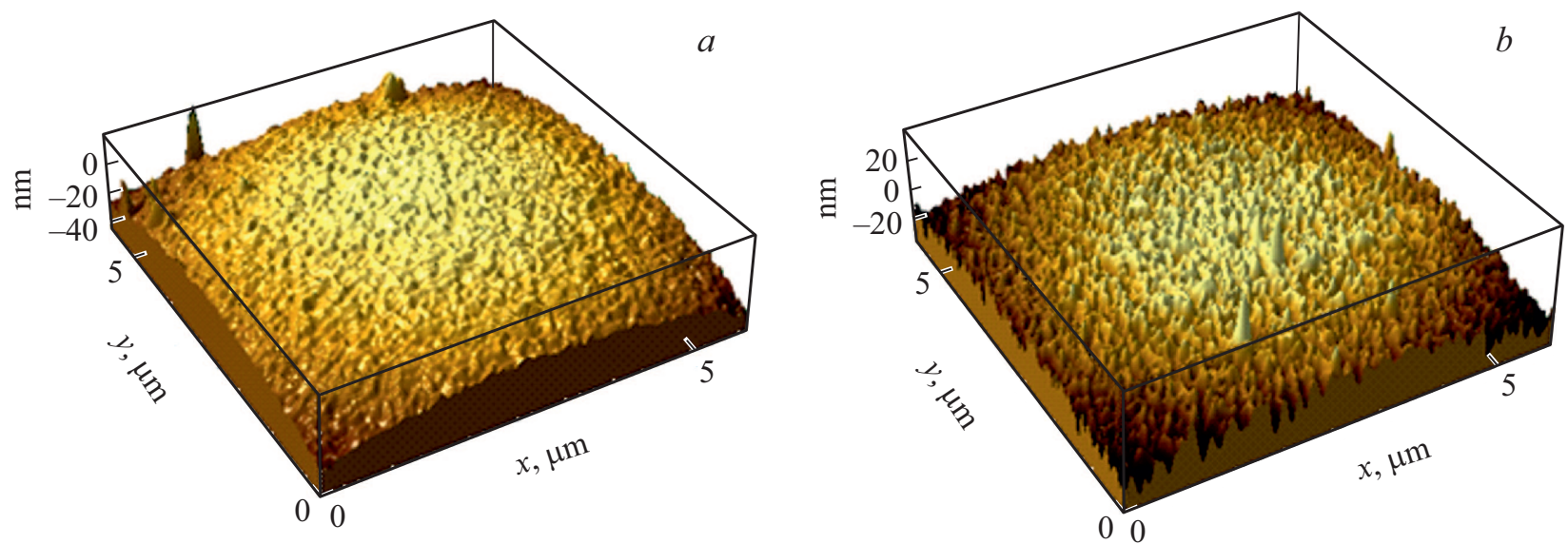

Рис. 3. Рельеф поверхности пленок, полученных на микросферах при различных разрядных мощностях: $a-50 \mathrm{~W}$ (аморфная), $b-140 \mathrm{~W}$ (кристаллическая).

В отличие от этого покрытия на микросферах того же состава, полученные при мощности разряда распылителя в диапазоне 75-480 W, имели столбчатую структуру, характерную для кристаллов. Пленки на сферах, которые по виду излома соответствуют металлическим стеклам, были получены только при наименьшей разрядной мощности $50 \mathrm{~W}$, отвечающей наименьшей температуре микросфер. На рис. 2, $a$ с различным увеличением представлено изображение излома пленки, полученной на сфере, с характерными признаками разрушения металлического стекла; для сравнения на рис. 2, $b$ приведен фрагмент кристаллической пленки того же состава, полученной на микросфере при высокой разрядной мощности. Сравнение этих результатов с полученными при нанесении пленок на плоские поверхности вкупе с данными оценки температуры микросфер, а также характерный состав $\mathrm{Pt}: \mathrm{Zr}=1: 4$ позволяют утверждать, что представленная на рис. 2, а пленка по структуре аморфна. Рельеф поверхности пленок, полученных на микросферах, показан на рис. 3. Шероховатость АМ-пленок на сферах по данным, полученным с помощью атомного силового микроскопа и оптического профилометра, находится в диапазоне $1-1.5 \mathrm{~nm}$, что существенно меньше, чем у кристаллических покрытий такого же состава $(5-7 \mathrm{~nm})$. Встречающиеся дефекты могут быть устранены за счет подготовки исходных поверхностей микросфер и оснастки рабочей камеры. Для АМ-пленок, в отличие от кристаллических, нарастание шероховатости с ростом их толщины не является обязательным атрибутом [11]. Скорость нанесения АМ-покрытий на микросферы в проведенном эксперименте была ограничена необходимостью поддержания низкой температуры и составляла $0.1 \mathrm{~nm} / \mathrm{s}$. Такая скорость характерна для получения кристаллических оболочек мишеней ИТС толщиной до $0.1 \mathrm{~mm}$ при магнетронном распылении [1,3]. Однако увеличение скорости нанесения для получения толстых покрытий остается актуальным. Решение проблемы в нашем случае мы предполагаем найти в увеличении мощности разряда при сохранении значения потока тепла на подложку за счет применения более сбалансированной магнитной системы распылителя [12]. Поэтому представляется возможным получить более толстые АМ-оболочки на сферах, соответствующие требованиям к оболочкам мишеней ИТС.

Таким образом, экспериментально установлены возможность и условия нанесения аморфной металлической 
оболочки на тонкостенные сферы с диаметром в диапазоне, соответствующем размерам внутренней оболочки двухоболочечной мишени ИТС.

\section{Благодарности}

В работе использовалось оборудование Учебнометодического центра литографии и микроскопии МГУ им. М.В. Ломоносова.

\section{Финансирование работы}

Работа выполнена при финансовой поддержке Российского фонда фундаментальных исследований (грант № 19-08-01250).

\section{Конфликт интересов}

Авторы заявляют, что у них нет конфликта интересов.

\section{Список литературы}

[1] H. Xu, H. Huang, J. Walker, C. Kong, N.G. Rice, M.P. Mauldin, J.D. Vocke, J.H. Bae, W. Sweet, F.H. Elsner, M.P. Farrell, Y.M. Wang, C. Alford, T. Cardenas, E. Loomis, Fusion Sci. Technol., 73 (3), 354 (2018). DOI: $10.1080 / 15361055.2017 .1387459$

[2] C. Horwood, M. Stadermann, T.L. Bunn, Fusion Sci. Technol., 73 (3), 335 (2018). DOI: 10.1080/15361055.2017.1387458

[3] H. Xu, C. Alford, E. Chason, A.J. Detor, T. Fuller, A.V. Hamza, J. Hayes, K.A. Moreno, A. Nikroo, T. Van Buuren, Y. Wang, J.J. Wu, H. Wilkens, K.P. Youngblood, J. Mater. Res., 27 (5), 822 (2012). DOI: 10.1557/jmr.2011.378

[4] А.Ф. Паль, А.Н. Рябинкин, А.О. Серов, Н.А. Дятко, А.Н. Старостин, А.В. Филиппов, ЖЭТФ, 141, (3), 608 (2012). http://www.jetp.ras.ru/cgi-bin/dn/r_141_608.pdf AA.F. Pal, A.N. Ryabinkin, A.O. Serov, N.A. Dyatko, A.N. Starostin, A.V. Filippov, JETP, 114 (3), 535 (2012). DOI: $10.1134 / \mathrm{S} 1063776112020276]$.

[5] P. Yiu, W. Diyatmika, N. Bönninghoff, Y.-Ch. Lu, B.-Zh. Lai, J.P. Chu, J. Appl. Phys., 127 (3), 030901 (2020). DOI: $10.1063 / 1.5122884$

[6] S.V. Ketov, X. Shi, G. Xie, R. Kumashiro, A.Y. Churyumov, A.I. Bazlov, N. Chen, Y. Ishikawa, N. Asao, H. Wu, D.V. Louzguine-Luzgin, Sci. Rep., 5 (1), 7799 (2015). DOI: $10.1038 /$ srep07799

[7] А.Ф. Паль, А.Н. Рябинкин, А.О. Серов, Письма в ЖТФ, 46 (14), 51 (2020). DOI: 10.21883/PJTF.2020.14.49669.18167 [A.F. Pal, A.N. Ryabinkin, A.O. Serov, Tech. Phys. Lett., 46 (7), 725 (2020). DOI: 10.1134/s1063785020070238].

[8] J.A. Thornton, Thin Solid Films, 54 (1), 23 (1978). DOI: 10.1016/0040-6090(78)90273-0

[9] V.I. Shapovalov, A.E. Komlev, A.S. Bondarenko, P.B. Baykov, V.V. Karzin, Phys. Lett. A, 380 (7-8), 882 (2016). DOI: $10.1016 /$ j.physleta.2015.12.021

[10] B.S. Murty, D.H. Ping, M. Ohnuma, K. Hono, Acta Mater., 49 (17), 3453 (2001). DOI: 10.1016/S1359-6454(01)00254-3

[11] Y.H. Liu, T. Fujita, A. Hirata, S. Li, H.W. Liu, W. Zhang, A. Inoue, M.W. Chen, Intermetallics, 21 (1), 105 (2012). DOI: 10.1016/j.intermet.2011.10.007

[12] B. Window, N. Savvides, J. Vac. Sci. Technol. A, 4 (2), 196 (1986). DOI: $10.1116 / 1.573470$ 